\title{
Reviving a Legacy Citizen Science Project to Illuminate Shifts in Bird Phenology
}

\author{
Jessica Zelt, ${ }^{1}$ Jason Courter, ${ }^{2}$ Ali Arab, ${ }^{3}$ Ron Johnson, ${ }^{2}$ and Sam Droege ${ }^{1}$ \\ ${ }^{1}$ USGS, Patuxent Wildlife Research Center, BARC-East, Building 308, 10300 Baltimore Avenue, Beltsville, MD 20705, USA \\ ${ }^{2}$ College of Agricultural, Forest, and Environmental Sciences, Clemson University, Lehotsky Hall Clemson, SC 29634, USA \\ ${ }^{3}$ Department of Mathematics and Statistics, Georgetown University, St. Mary's Hall, 37th and O Streets, NW Washington, \\ DC 20057, USA
}

Correspondence should be addressed to Jessica Zelt, jzelt@usgs.gov

Received 2 March 2012; Accepted 26 April 2012

Academic Editor: Richard Stafford

Copyright ( $\odot 2012$ Jessica Zelt et al. This is an open access article distributed under the Creative Commons Attribution License, which permits unrestricted use, distribution, and reproduction in any medium, provided the original work is properly cited.

Climate change has been of high interest to both the scientific community and the public at large since the phenomenon was first suggested. Subsequently, and with growing evidence of its impending ramifications, numerous studies have attempted to illuminate climate change impacts on bird migration. Migration is a key event in the annual cycle in the reproductive success of birds, and changes in migration in response to climate may indicate that species populations are at risk. Previous studies report earlier arrival dates in response to climate change in many bird species, although specific mechanisms are often difficult to explain at broad spatial and temporal scales. Using a newly revived dataset of historical migration cards for over 870 species and spanning 90 years throughout North America, we are developing an historical baseline of bird arrival dates to compare with contemporary records. Here we chronicle the history and reemergence of the North American Bird Phenology Program. We present two case studies illustrating how data from this program has been used to model historical arrival dates of Ruby-Throated Hummingbird (Archilochus colubris) and Purple Martin (Progne subis) throughout eastern North America. Our results show the importance of considering spatial and temporal variability in understanding patterns of bird spring arrivals.

\section{Introduction}

Climate change is a leading threat to the survival of species and integrity of ecosystems [1], and in response to climate change, bird migration times are changing throughout much of the world [2]. Shifting spring arrivals have been documented in North America, Eurasia, and Australia for a broad range of species and locations [3]. Not only are birds showing advancement in their arrivals to breeding grounds, but also are departing later in the autumn [47]. Migratory changes have been correlated to changing temperatures in wintering grounds, breeding grounds, and along migration routes and to a variety of other variables such as rainfall, humidity, and wind speed [1]. Migration must align with favorable environmental conditions to reduce the stress incurred through mistiming arrivals with maximal food abundance and vegetation growth $[8,9]$. If not, migratory changes can negatively impact reproduction and survival [10]. Phenology, the study of the timing of seasonal life cycle stages, is one of the simplest ways to track biological changes of species in response to climate change [3]. Because phenological sequences in birds often rely on environmental stimuli to spur arrivals and departures, studies of bird phenology are often used by ecologists to assess the possible impact of climate change on wildlife species [11].

Precise relationships between climate variables and migration times remain difficult to assess because many phenological records are from small geographic areas, recent time periods, and/or contain only small subsets of species. While citizen science efforts have long provided important information for studying long-term range shifts in birds over expansive geographic ranges (e.g., the Christmas Bird Count, the Breeding Bird Survey), a similar large-scale effort that provides data to assess changes in phenology has long been lacking. 
In this paper we introduce or, to a few, reintroduce, the North American Bird Phenology Program (BPP), a citizen science program, unsurpassed in geographic, taxonomic, and chronological extent; the BPP houses the most comprehensive legacy dataset in the world for bird migration. This data set contains several million historical arrival and departure records for migratory birds, collected between 1881 and 1970 by leading naturalists and the general public. Although first envisioned to study the distribution and migration of birds, it is now being adapted to investigate shifts in bird arrivals over time, a question with enormous ecological implications. Here we chronicle the history and reemergence of the BPP and present two case studies to demonstrate the potential usefulness of this dataset. Of particular interest to this special edition is the use of citizen volunteers to both collect the original data and now input historical records into digital databases for future analysis.

\section{History of the BPP}

In 1881, Wells Woodbridge Cooke, a Mississippi teacher interested in the seasonal movements of birds, started a regional cooperative collection of records with acquaintances and colleagues throughout the Mississippi Valley, to document first arrival dates, dates of highest abundance, and last seen dates of all migratory birds [12]. With the support of the American Ornithologists' Union (AOU), Cooke expanded the cooperative which grew to 3,000 participants at the program's height [12]. Participants consisted of both prominent naturalists as well as citizens interested in collecting data for a scientific study. This growth also expanded the geographic range of the volunteer network to include the entire United States, Canada, and a portion of the West Indies. The program was then picked up, in the late 1880s, by the newly formed United States Department of Agriculture (USDA) Biological Survey, where participation peaked, before being passed onto the predecessors of the United States Fish and Wildlife Service (USFWS) and later the United States Geological Survey (USGS) in the Department of the Interior. Cooke relocated to the Washington D.C. area with the survey and became a naturalist for the USDA using the records collected to understand migratory bird patterns, geographic ranges, and basic avian behavior. After Cooke's death in 1916, the program was subsequently guided by other coordinators whom carefully tended and added to the records in the files. Throughout the period of data collection, protocol was instructed and guided by the program coordinator and remained largely consistent though the formatting changed with technological advances. In sum, records on bird migration, breeding, wintering, and distribution for over 870 species were collected over a 90 year span and served as the basis for the AOU's Check-list of North American Birds and sources of information for the first ornithological field guides [12-14]. Although the federal government actively maintained the program, participation gradually declined, and in 1970 the program came to an end as private sector bird watching groups became interested and active in maintaining bird distribution and migration records. This once formidable program was largely forgotten after years of little use recognition and sat idle for over 40 years. In March of 2008, the program was revived in response to nationwide concerns about changes in bird phenology as a result of climate change and the unique opportunity these cards offered to providing documented evidence of possible changes. Funding was limited; however, because the majority of records were handwritten in various formats, they could not simply be converted into a usable digital form using optical character recognition. Records were therefore scanned as image files, later to be displayed online through a data entry interface for transcription by the general public. After months of scanning records inhouse, the public website was launched in February of 2009. The program currently relies on a growing worldwide network of over 2,500 volunteers to complete a doubleblind transcription of each record, which upon matching is sent into a custom built database. To date, over one million records have been scanned and 500,000 cards transcribed online. Once validated, the records will be accessible online by biologists, managers, and members of the general public.

\section{Volunteer Recruitment, Training, and Data Management}

Volunteers for the BPP program have been recruited through media outreach, presentations at local and national ornithological meetings, and by word-of-mouth. Volunteers of all abilities and ages are invited to become BPP transcribers, as long as they have Internet access and a web browser [15]. After registering with the program, each volunteer must watch a 15-minute training video that explains how to transcribe different versions of the migration cards. Then, using a web-based application, observation card images are selected from the pool of cards available for transcription by the volunteer. An observation card can be selected at random or filtered for a desired state or species. Volunteers transcribe the contents of the cards by filling in fields of an online form. Each card is entered by at least two independent volunteers for quality assurance. When the two entries for the card match, the data are sent into the BPP database. If the two entries do not match, or if a transcriber marks the card as a "problem card," the card is flagged and reviewed in the BPP office.

Volunteers can track their individual progress as well as the progress of the volunteer community through an expandable window on the transcription screen and through charts viewable on the main website. Volunteers are ranked based on the number of cards they submit and receive recognition for their contribution through email, certificates, prizes, and mention in the BPP monthly newsletter.

\section{Case Study 1: Modeling Ruby-Throated Hummingbird Arrival Dates across Eastern North America}

Ruby-throated Hummingbirds (Archilochus colubris) are charismatic, neotropical migrants that have fascinated naturalists for centuries [15]. They are easily identified and the 


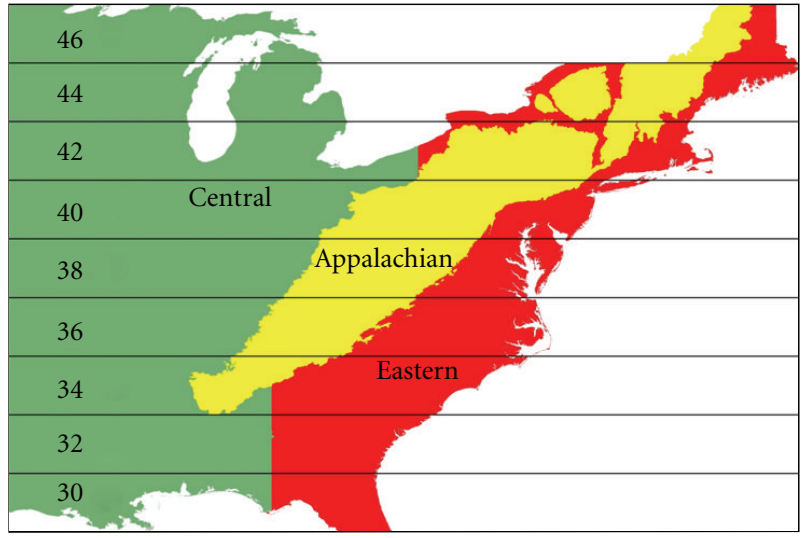

Figure 1: Our study area $\left(29-47^{\circ} \mathrm{N}, 67-95^{\circ} \mathrm{W}\right)$ divided into three regions based on classifications used by the Breeding Bird Survey (http://www.pwrc.usgs.gov/bbs/) and the Environmental Protection Agency (Level III Ecoregions; http://www.epa.gov/wed/ pages/ecoregions/level_iii_iv.htm).

only regularly reported hummingbird in eastern North America, making them suitable targets for long-term monitoring programs. Hummingbirds winter in Central America between northern Panama and southern Mexico and most migrate across the Gulf of Mexico, arriving at their breeding grounds in North America between February-April [15] where they help pollinate at least 31 plant species [16]. Recent studies indicate that hummingbirds are arriving earlier to their breeding grounds than in historical time periods in some places (e.g., Maine [17]; Massachusetts $[18,19]$; South Dakota [20]; and New York [18]), but not others (Minnesota [20]). Proposed mechanisms for such changes include climate change, increasing hummingbird populations, and an increase in popularity of backyard birdfeeding. It remains difficult to explain possible mechanisms for changes, however, when examining migration at site- or region-specific scales.

Recent hummingbird migration patterns are becoming well-documented throughout North America, thanks to emerging networks of citizen science observers reporting first arrivals online through popular websites such as Journey North (http://www.learner.org/jnorth/), hummingbirds.net, and eBird (http://ebird.org/content/ebird/). At the same time, changes in climate $[21,22]$ and land-use $[23,24]$ have also been well documented as mapping technology (e.g., United States Geological Survey Land Cover Institute http:// landcover.usgs.gov/usgslandcover.php) and historical climate data have become widely accessible (e.g., the Nature Conservancy's Climate Wizard http://www.climatewizard .org/). Both migration and environmental data are needed to understand how meteorological conditions and landuse influence bird migration at broad spatial scales, but to understand bird migration across both space and time, we need to better understand how bird migration occurred historically. Until recently, a continent-wide baseline to compare with recent arrivals has been largely unavailable.

The objective of this study is to demonstrate how data from the recently revitalized North American Bird
Phenology Program (BPP) can be used to generate an historical understanding of migration in Ruby-throated Hummingbirds. This understanding could help prompt future studies that assess changes in bird migration at broad spatial and temporal scales in response to climate and landuse changes.

First arrival dates of Ruby-throated Hummingbirds in eastern North America $\left(29-47^{\circ} \mathrm{N}, 67-95^{\circ} \mathrm{W}\right)$ were transcribed from arrival cards reported through the North American Bird Phenology Program. Each arrival location was then assigned a location (i.e., latitude, longitude, and altitude) based on the centroid of the reported arrival city using the GPS visualizer geocoding service (http://www .gpsvisualizer.com/). Longitudinally, arrival records east of $95^{\circ} \mathrm{W}$ (approximate range limit for Ruby-throated Hummingbirds) were divided into Central, Appalachian, and Eastern Regions (Figure 1). Regions were delineated based on categories used by the Breeding Bird Survey and the Environmental Protection Agency (Level III Ecoregions; http://www.epa.gov/wed/pages/ecoregions/level_iii_iv.htm).

In sum, we analyzed 5,065 first arrival records from the BPP card files between 1880 and 1969. We used multiple regression to assess the effects of latitude, longitude, and altitude on hummingbird arrival dates in the eastern United States and ANOVA to assess the differences in mean hummingbird arrival dates by region (Central, Appalachian, Eastern) while including latitude as a covariate. It should be noted that these findings are preliminary and based on statistical methods with strict assumptions about the data (e.g., independence) that are difficult to meet due to potential dependence structures over space and time.

Our model (adjusted $r^{2}=0.66, F_{3,5061}=3267.1, P<$ 0.0001 ) indicated that latitude, longitude, and altitude were related to hummingbird arrival dates. In summary, from 1880-1969, hummingbirds arrived 3.4 days later for every $1^{\circ}$ increase in latitude, 1.2 days later for every $10^{\circ}$ longitude increment, moving from west to east, and 7.5 days later for every $1000 \mathrm{~m}$ increase in elevation. Mean arrival dates also differed by region (Figure 1), with birds arriving $1.3 \pm 0.33$ S.E. days earlier in the central United States than in the Appalachian Region $(P<0.0001)$ and $1.1 \pm 0.27$ S.E. days earlier in the central United States than in the Eastern Region $(P<0.0001)$. No significant differences in arrival dates were noted between the Appalachian and Eastern Regions $(P=$ 0.52; Figure 2).

Earlier arrivals in the central United States (Figure 2) could be explained by a difference in travel distance with central migrants travelling directly north from Gulf States where many hummingbirds make landfall (i.e., Alabama, Mississippi, Louisiana) [15] and eastern migrants travelling northeast, a less direct route. Another possibility is that central migrants may have migrated over land (i.e., Mexico and Texas) [15], perhaps requiring less time to refuel than their eastern counterparts making dangerous and exhausting trips across the Gulf of Mexico. Later arrivals in mountainous regions are not surprising [25] given that melting snowpack and cooler spring temperatures can delay spring phenology at high latitudes [26]. 


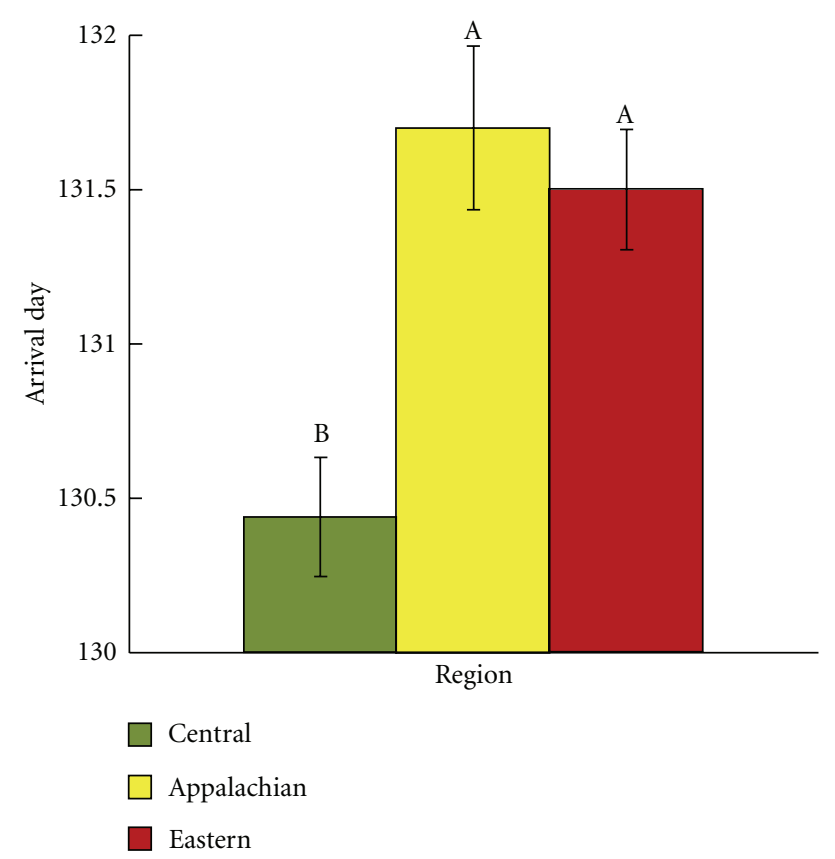

Figure 2: Difference in mean first arrival dates ( \pm S.E.) of Rubythroated Hummingbirds in the Central $(N=2002)$, Appalachian $(N=1075)$, and Eastern Regions $(N=1988$; see Figure 1 for region designations). Arrival days are expressed in "day of year" and corrected for leap years; for example, "130" corresponds to May 10. Inset letters represent differences that are significant at the $P<0.05$ level.

Our findings highlight the importance of considering spatial variables such as altitude and region in studies of phenology and provide a basis for a number of future research questions. For example, are hummingbirds tracking recent climate change events? Does climate change slow or speed up migration in hummingbirds? Do hummingbirds increase stopover periods in areas such as mountains that are disproportionately affected by warming climates [27]. Where are changes in migration most pronounced and are these changes synchronized across food webs (e.g., birds, insects, plants)? Have these changes impeded or enhanced pollination services hummingbirds provide?

Efforts such as the North American Bird Phenology Program help provide the missing puzzle piece of data for understanding historical migration patterns. As recent migration data emerge along with more sophisticated tools to assess climate and land use changes of the past century, the availability of historical data allows us to better understand changes in bird phenology and related global changes at broad temporal and spatial scales.

\section{Case Study 2: Changes in Purple Martin Arrival Dates}

Purple Martins (Progne subis) are the largest member of the swallow family in North America. They spend their nonbreeding season in Brazil and migrate to North America to nest. Adults commonly return to the same nesting sites

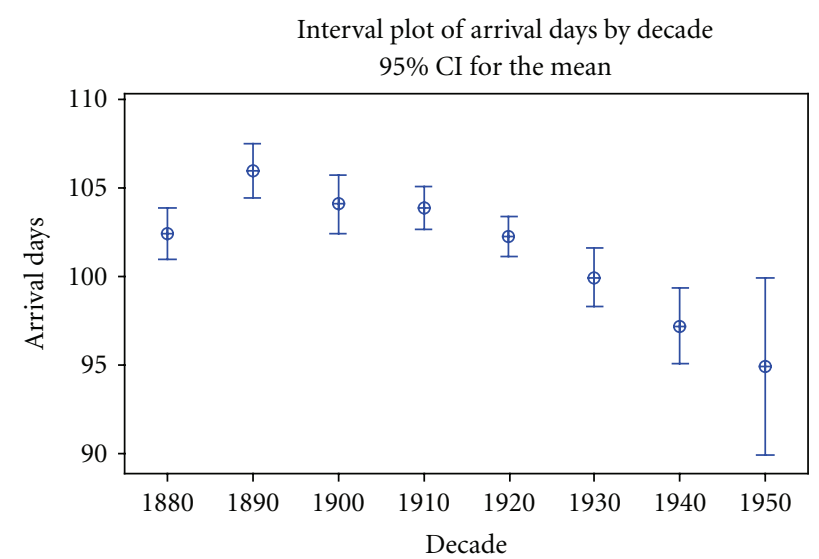

FIGURE 3: Interval plot for the mean arrival days for decades 1880 1950. Intervals show the $95 \%$ confidence interval for the mean decadal arrival dates. Arrival days are expressed in "day of year" and corrected for leap years; for example, "90" corresponds to March 29. The sample sizes for decades are 501 (1880s), 565 (1890s), 700 (1900s), 1126 (1910s), 1152 (1920s), 738 (1930s), 444 (1940s), 119 (1950s).

where they were successful in previous years. These adult martins arrive to their nesting grounds a few weeks before subadults arrive to establish new nesting sites. Once a pair is established, they cooperate equally in building the nest out of mud, grass, and twigs. This species is of special interest to birders, in large part, because of the close proximity of their nesting sites to human settlements [28].

Based on an initial dataset of 5,345 Purple Martin arrival records provided by the BPP, arrival dates were aggregated over each decade, from the 1880s through the 1950s. We found that the arrival dates for 1920s, 1930s and 1940s were statistically earlier than the arrival dates for the 1880 s through 1910s (Figure 3) (a randomized block analysis of variance (ANOVA) of the arrival days using "decade" as the main effect and "latitudinal band" as the blocking effect showed the main effect (decade) to be statistically significant at 0.05 level $(P<0.0001))$. Reforestation in the northeast during the beginning of the 20th century [29] and increasing use of artificial martin houses [30] may have increased martin populations during this time and may partially explain migratory advancements noted [31]. Increased competition for nest cavities with introduced species, such as European Starlings (Sturnus vulgaris) and House Sparrows (Passer domesticus) [32], may also be associated with advancing martin migration dates. Finally, it should also be noted that the relatively large standard error for the 1950s data in Figure 3 is due to relatively lower sample size (119 observations) than the previous decades.

We conducted a change point analysis of the mean arrival dates for latitudinal degree groups (total of 15 groups) in the 1880s-1950s. The groups were assigned so each group had data from each decade. The change point analysis was conducted based on the method proposed by Allen and Nice [31] and the functions available through the package MCMCpack in the freely distributed software $\mathrm{R}$ 
(http://www.r-project.org/). Using this method, for all time series and latitudinal groups, the most probable change points selected were the 1890s and 1900s. In most cases, there was a decline in the mean arrival dates after the 1900s.

\section{Discussion of Future Analysis Using BPP Data}

Previous approaches to predict species' responses to climate change have generally addressed migratory changes at broad spatial or temporal scales, but rarely both, because of the insufficient availability of long-term or spatially extensive data sets [1]. Also, there is increasing interest to understand potential association between spatial, temporal, or spatiotemporal "change-points" or "tipping-points" of environmental processes, such as the bird arrival process, and changes in the earth's climate. Needs for these datasets are urgent and the BPP dataset provides a unique baseline that more recent data on bird phenology can be compared. The original BPP dataset covers 90 years, and by integrating it with contemporary records of first arrival dates, we can evaluate 130 years of spatial, temporal, and interspecific variation in bird phenology across the United States and Canada. This could provide unprecedented insight into the migratory behavior of birds and its relationship to climate and environmental changes.

Future research studies are being planned to investigate changes in arrival dates of species at site-based and national scales while using elevation and climate variables to explain temporal and spatial variation in migration times and strengthen the conclusions presented here. This dataset could facilitate understanding of ecosystem responses to climate change and be used to develop decision support tools for avian and habitat management plans in the face of climate variability and directional change. These data will also contribute to our understanding of patterns and processes related to bird-related diseases, such as avian influenza, that can be affected by changing migration phenology and may also impact human health. In addition, these data could assist modelers in developing species vulnerability assessments-phenology can indicate the likelihood that a population will decline in size in response to climate change $[33,34]$. Because phenology is related to population distributions, these data could be used to create tools for ecological forecasting and risk assessment for imperiled species as well as helping researchers identify which species are more adaptable to projected changes and likely to maintain sustainable populations.

Historical data, such as those preserved by the BPP, are of special importance because they are irreplaceable. This particular dataset provides a wealth of information about bird migration, and converting it to a digitally usable format is the first step to making it widely useful and accessible. Collecting and then transcribing original records over 130 years later has only been possible by relying on participants from around the world to assist in this process. Through standardized protocols and the collective effort of the public, the scope of this monitoring program has been magnified beyond any capability the government would have had to collect or transcribe data. As such, we have created a public/private partnership in which a dedicated team of governmental employees and academics have created an appropriate home and structure for the data, and members of the general public have collected and transcribed data; each making important contributions to a project that will ultimately help us better understand large-scale ecological processes that affect us all.

\section{Acknowledgments}

The authors are much indebted to the original observers who collected the extensive data used here as well as the thousands of volunteers who have contributed to transcribing the data into our database. The North American Bird Phenology Program relies heavily on the work of volunteers around the globe and we could not accomplish what we have without them. There are many individuals besides the authors of this paper who have provided guidance and support to the BPP, including Chandler Robbins, Jane Fallon, John R. Sauer, Kevin Laurent, Kinard Boone, and Lynda Garrett. The development of the North American Bird Phenology Program has been supported with grants from the National Oceanic and Atmospheric Administration, United States Fish and Wildlife Service, the United States Geological Survey, and the Maryland Ornithological Society. They also thank Clemson University, with additional support from a Carolina Bird Club grant, for funding the work presented in the hummingbird case study.

\section{References}

[1] P. E. Hulme, "Adapting to climate change: is there scope for ecological management in the face of a global threat?" Journal of Applied Ecology, vol. 42, no. 5, pp. 784-794, 2005.

[2] E. Lehikoinen, T. H. Sparks, and M. Zalakevicius, "Arrival and Departure Dates," Advances in Ecological Research, vol. 35, pp. 1-31, 2004.

[3] Intergovernmental Panel on Climate Change (IPCC), "Impacts, adaptation and vulnerability," in Contribution of Working Group II to the Fourth Assessment Report of the IPCC, M. L. Parry, O. F. Canziani, J. P. Palutikof, P. J. van der Linden, and C. E. Hanso, Eds., pp. 98-101, Cambridge University Press, Cambridge, UK, 2007.

[4] L. Jenni and M. Kéry, "Timing of autumn bird migration under climate change: advances in long-distance migrants, delays in short-distance migrants," Proceedings of the Royal Society B, vol. 270, no. 1523, pp. 1467-1471, 2003.

[5] C. Parmesan and G. Yohe, "A globally coherent fingerprint of climate change impacts across natural systems," Nature, vol. 421, no. 6918, pp. 37-42, 2003.

[6] T. L. Root, J. T. Price, K. R. Hall, S. H. Schneider, C. Rosenzweig, and J. A. Pounds, "Fingerprints of global warming on wild animals and plants," Nature, vol. 421, no. 6918, pp. 5760, 2003.

[7] A. Menzel, T. H. Sparks, N. Estrella et al., "European phenological response to climate change matches the warming pattern," Global Change Biology, vol. 12, no. 10, pp. 1969-1976, 2006. 
[8] S. Pau, E. M. Wolkovich, B. I. Cook et al., "Predicting phenology by integrating ecology, evolution and climate science," Global Change Biology, vol. 17, pp. 3633-3643, 2011.

[9] R. L. DeLeon, E. E. DeLeon, and G. R. Rising, "Influence of climate change on Avian Migrants' first arrival dates," Condor, vol. 113, no. 4, pp. 915-923, 2011.

[10] M. C. Forchhammer, E. Post, and N. C. Stenseth, "North Atlantic Oscillation timing of long- and short-distance migration," Journal of Animal Ecology, vol. 71, no. 6, pp. 1002-1014, 2002.

[11] S. B. Smith and P. W. C. Paton, "Long-term shifts in autumn migration by songbirds at a coastal eastern north American stopover site," Wilson Journal of Ornithology, vol. 123, no. 3, pp. 557-566, 2011.

[12] T. S. Palmer, "In Memoriam: wells woodbridge cooke," The Auk, vol. 34, no. 2, pp. 119-132, 1917.

[13] D. Sam, "Interview with Chandler S. Robbins," in The North American Bird Phenology Program Website, USGS Patuxent Wildlife Research Center, Laurel, MD, USA, 2009.

[14] J. A. Allen, "The A.O.U. check-list of North American birds, third edition," The Auk, vol. 27, no. 4, pp. 466-472, 1910.

[15] United States Geological Survey, "North American Bird Phenology Program," 2008, http://www.pwrc.usgs.gov/bpp/.

[16] T. R. Robinson, R. R. Sargent, and M. B. Sargent, "Rubythroated Hummingbird (Archilochus colubris)," in The Birds of North America Online, A. Poole, Ed., Cornell Lab of Ornithology, Ithaca, NY, USA, 1996.

[17] D. Austin, "Bird flowers in the eastern United States," Florida Scientist, vol. 38, pp. 1-12, 1975.

[18] W. H. Wilson Jr., D. Kipervaser, and S. A. Lilley, "Spring arrival dates of Maine migratory breeding birds: 1994-1997 vs. 18991911," Northeastern Naturalist, vol. 7, pp. 1-6, 2000.

[19] C. J. Butler, "The disproportionate effect of global warming on the arrival dates of short-distance migratory birds in North America," Ibis, vol. 145, no. 3, pp. 484-495, 2003.

[20] A. Ledneva, A. J. Miller-Rushing, R. B. Primack, and C. Imbres, "Climate change as reflected in a naturalist's diary, Middleborough, Massachusetts," Wilson Bulletin, vol. 116, no. 3, pp. 224-231, 2004.

[21] D. L. Swanson and J. S. Palmer, "Spring migration phenology of birds in the Northern Prairie region is correlated with local climate change," Journal of Field Ornithology, vol. 80, no. 4, pp. 351-363, 2009.

[22] T. R. Karl and K. E. Trenberth, "Modern Global Climate Change," Science, vol. 302, no. 5651, pp. 1719-1723, 2003.

[23] S. R. Loarie, P. B. Duffy, H. Hamilton, G. P. Asner, C. B. Field, and D. D. Ackerly, "The velocity of climate change," Nature, vol. 462, no. 7276, pp. 1052-1055, 2009.

[24] J. A. Foley, R. DeFries, G. P. Asner et al., "Global consequences of land use," Science, vol. 309, no. 5734, pp. 570-574, 2005.

[25] E. C. Ellis, K. K. Goldewijk, S. Siebert, D. Lightman, and N. Ramankutty, "Anthropogenic transformation of the biomes, 1700 to 2000," Global Ecology and Biogeography, vol. 19, no. 5, pp. 589-606, 2010.

[26] T. H. Sparks and O. Braslavská, "The effects of temperature, altitude and latitude on the arrival and departure dates of the swallow Hirundo rustica in the Slovak Republic," International Journal of Biometeorology, vol. 45, no. 4, pp. 212-216, 2001.

[27] D. W. Inouye, B. Barr, K. B. Armitage, and B. D. Inouye, "Climate change is affecting altitudinal migrants and hibernating species," Proceedings of the National Academy of Sciences of the United States of America, vol. 97, no. 4, pp. 1630-1633, 2000.
[28] J. C. Fyfe and G. M. Flato, "Enhanced climate change and its detection over the rocky mountains," Journal of Climate, vol. 12, no. 1, pp. 230-243, 1999.

[29] C. R. Brown, "Purple Martin (Progne subis)," in The Birds of North America Online, A. Poole, Ed., Cornell Lab of Ornithology, Ithaca, NY, USA, 1997.

[30] J. A. Litvaitis, "Response of early successional vertebrates to historic changes in land use," Conservation Biology, vol. 7, no. 4, pp. 866-873, 1993.

[31] R. W. Allen and M. M. Nice, "A study of the breeding biology of the Purple Martin (Progne subis)," American Midland Naturalist, vol. 47, pp. 606-665, 1952.

[32] A. J. Miller-Rushing, T. L. Lloyd-Evans, R. B. Primack, and P. Satzinger, "Bird migration times, climate change, and changing population sizes," Global Change Biology, vol. 14, no. 9, pp. 1959-1972, 2008.

[33] S. Chib, "Estimation and comparison of multiple changepoint models," Journal of Econometrics, vol. 86, no. 2, pp. 221241, 1998.

[34] A. P. Møller, D. Rubolini, and E. Lehikoinen, "Populations of migratory bird species that did not show a phenological response to climate change are declining," Proceedings of the National Academy of Sciences of the United States of America, vol. 105, no. 42, pp. 16195-16200, 2008. 

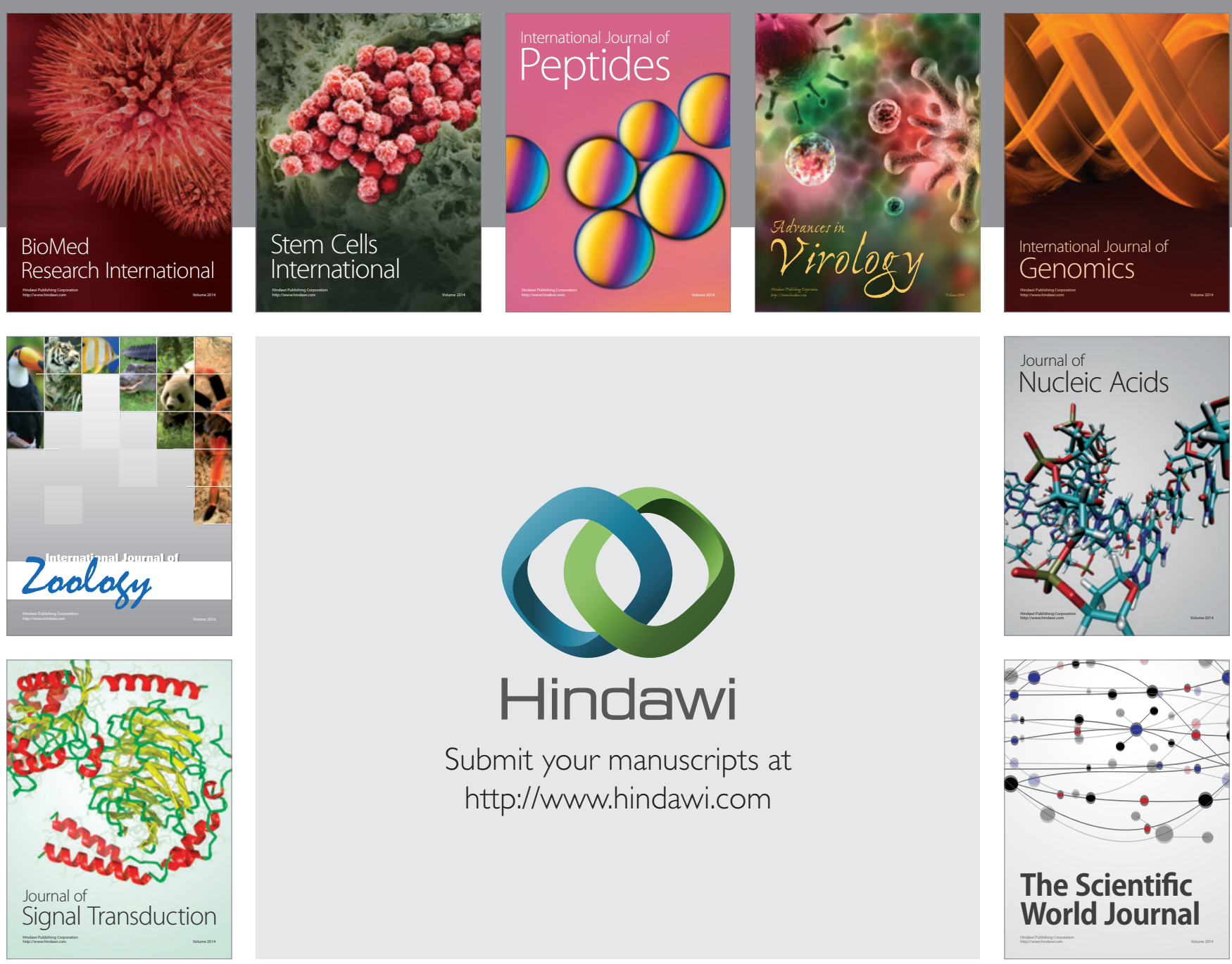

Submit your manuscripts at

http://www.hindawi.com
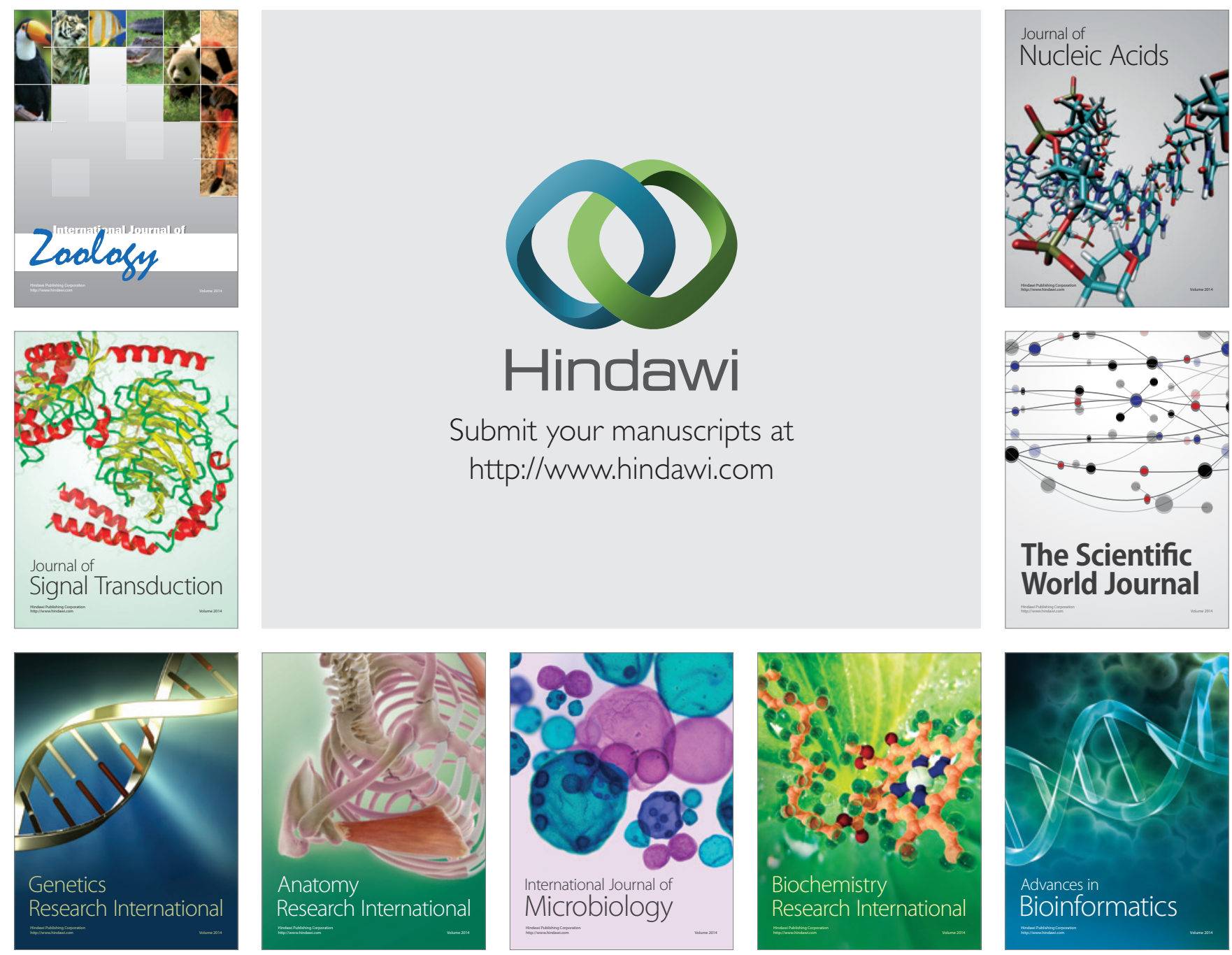

The Scientific World Journal
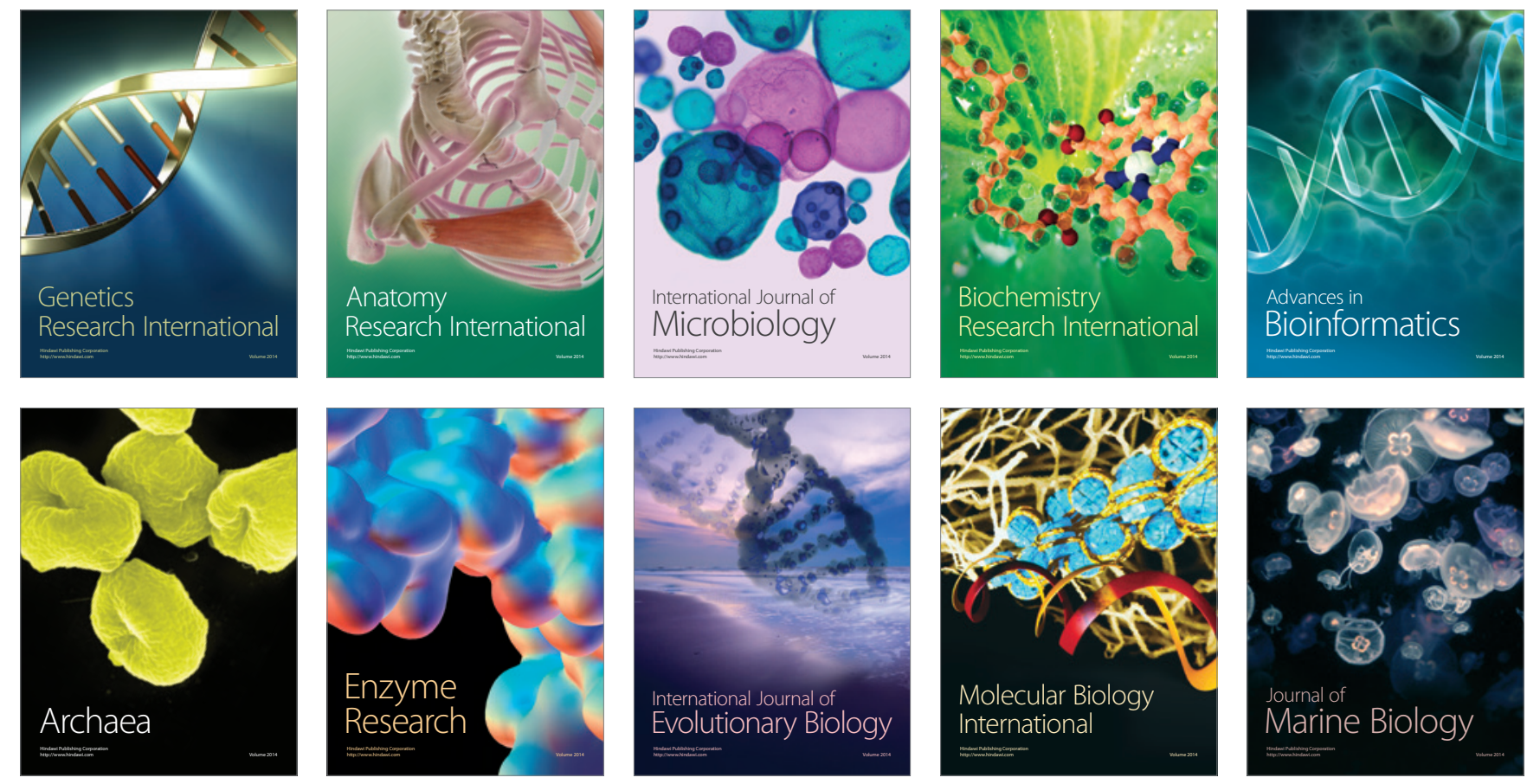